\title{
Genel Cerrah Perspektifinden Ilimizin İlk Yanık Birimi Pratiği
}

\section{The First Burns Unit Practice in Our Province from the Perspective of $A$ General Surgeon}

\author{
Emil HÜSEYINOĞLU ${ }^{1}$ (D), Serdar KIRMIZI ${ }^{2}$ \\ ${ }^{1}$ Genel Cerrahi, Yozgat Şehir Hastanesi, Yozgat, Türkiye. \\ ${ }^{2}$ Gastroenteroloji Cerrahi, Yozgat Şehir Hastanesi, Yozgat, Türkiye.
}

Öz.

Amaç: ilimizin ilk yanık tedavi birimi deneyimini paylaşarak yanık yaralanmalarının tedavisinde "yanık odasının" önemini vurgulamak amaçlandı.

Materyal ve metod: Çalışma Haziran 2020- Nisan 2021 tarihleri arasında Yozgat Şehir Hastanesi'nde retrospektif olarak gerçekleştirildi. Bu süreç içerisin de yanık birimimizde yatırılarak veya ayaktan tedavi edilen hastalar çalışmaya dahil edildi. Hastaların yaş, cinsiyet, yanık nedeni, toplam yanık yüzey alanı, yanık bölgesi, hastane yatış süresi, uygulanan tedavi yöntemleri elektronik kayıtlı hasta verilerinden belirlendi.

Bulgular: Toplam 107 hasta ayaktan veya yatırılarak tedavi edildiği, bunların 57'sinin (\% 53,3) erkek, 50'sinin (\% 46,7 ) kadın ve ortanca yaş değerinin 24 (aralık, 1-88) olduğu görüldü. Tüm yanık yaralanmalarının, $85^{\prime}$ i $(\% 79,4$ ) haşlanma, 21'i (\% 19,6) alev ve 1'i $(\% 0,9)$ elektrik kaynaklıydı. Yanık derinliği yönünden en sık karşısaşılan 2.dereceden derin yanıklardı ve 58 (\% 54,2) hastada saptandı. Gövde bölgesi en sık etkilenen bölgeydi ve 47 $(\% 45,8)$ hastada görüldü. Yanık yaralanmalarının 43'ü $(\% 40,2)$ yatıılarak tedavi edildiği, yatış süreleri ortanca 3 gün (1-90) olduğu saptandı. Yatarak tedavi alan hastaların 24 'ünü $(\% 55,8)$ haşlanma, $18^{\prime}$ ini $(\% 41,9)$ alev yanıkları ve 1 'ini $(\% 2,3)$ elektrik yanıkları oluşturmaktaydı. Yatan hastaların 33'üne $(\% 76,7)$ standart pansuman tedavisinin, 4 'üne $(\% 9,3)$ greft tedavisinin ve 6 'sına (\% 14) plasenta uygulamasının yapıldığı görüldü. Hastaların hiçbirinde mortalite görülmedi.

Sonuç: Birçok yanık yaralanmasının, yetkin bir ekiple "yanık odası" birimlerinde başarıla tedavi edilmesi, ileri yanık merkezlerine gereksiz sevkleri önemli oranda azaltılacaktır. Böylece bu merkezlerin iş yükü azaltılmış ve ülke kaynakları daha verimli kullanıımıs olacaktır.

Anahtar Kelimeler: Yanık; yanık yaralanması; yanık birimi; yanık tedavisi.

Abstract

Background: To share the first burn unit practice in Yozgat province and emphasize the importance of the "burns unit" in the treatment of burn injuries.

Materials and Methods: The study was carried out retrospectively at Yozgat City Hospital between June 2020 and April 2021. The patients who were inpatient or outpatient in our burns unit during this period were included in the study. Patients' age, gender, cause of the burn, total burn surface area, burn location, length of hospital stay, treatment methods were determined from electronically recorded patient data.

Results: A total of 107 patients were treated as outpatients or inpatients, 57 (53.3\%) were male, 50 (46.7\%) were female, and the median age was 24 (range, 1-88). Of all burn injuries, 85 (79.4\%) were caused by scalding, 21 $(19.6 \%)$ from flame, and $1(0.9 \%)$ from electricity. In terms of the burn severity, the most common was seconddegree burns and were determined in $58(54.2 \%)$ patients. The trunk was the most frequently affected area and was seen in $47(45.8 \%)$ patients. Of the burn injuries, $43(40.2 \%)$ were treated by hospitalization and the median length of stay was 3 days (1-90). Of the inpatients, $24(55.8 \%)$ were scalded, $18(41.9 \%)$ had flame burns, and 1 (2.3\%) had electrical burns. It was found that standard medical dressing treatment was applied to $33(76.7 \%)$ of the hospitalized patients, graft treatment was applied to $4(9.3 \%)$, and placenta application was applied to the burned area in $6(14 \%)$ patients. No mortality was seen in any of the patients.

Conclusions: A successful treatment of many burn injuries in "burns room" units with a competent team will significantly decrease unnecessary referrals to advanced burn centers. Thus, the workload of these centers will be reduced and the country's resources will be used more efficiently.

Keywords: Burn; burn injury; burn unit; burn treatment.
Sorumlu Yazar / Corresponding Author

Dr. Serdar KIRMIZI

Gastroenteroloji Cerrahi, Yozgat Şehir Hastanesi, Yozgat, Türkiye

e-mail:

drserdarkirmizi@hotmail.com

Geliș tarihi / Received:

27.04.2021

Kabul tarihi / Accepted: 24.08.2021

DOI: $10.35440 /$ hutfd. 928745 


\section{Giriş}

Yanık yaralanmaları, dünya genelinde psikolojik, sosyal ve ekonomik etkileri olan önemli bir travmadır. Günümüzde teknolojik gelişmelere paralel olarak yanık çeşitliliği de artmıştır. Etiyolojik nedenleri; sosyo-ekonomik, kültürel ve eğitim durumuna göre değişmektedir (1). Yanık vakaları yanık yüzey alanı, yanık derinliği, yanık bölgesi ve etiyolojik özellikleri (kimyasal, elektrik, inhalasyon vb.) göz önünde bulundurularak hafif, orta veya ağır olarak sınıflandırılır. Bu sınıflamaya göre hastalar sevk basamağına uygun olarak sırasıyla "yanık odası", "yanık ünitesi" veya "yanık merkezi"ne yönlendirilmektedir (2). Özellikle yanık merkezlerinde tedavi edilen ağır yanık hastalarının gerek tekrarlayan cerrahi işlemler gerek septik komplikasyonlar nedeniyle uzun hastane yatışları söz konusudur (3). Eğer hafif ve bazı orta derecede yanık yaralanmaları yanık odası birimi bulunan hastanelerde tedavi edilirse, ağır yanık hastalarına hizmet veren yanık merkezlerinin iş yükü azaltılmış olacaktır $(4,5)$. Böylece mevcut kaynaklar en etkili şekilde kullanılmış ve yanık tedavisinde daha başarılı sonuçlara ulaşılmış olunacaktır. Bu çalışmayla ilimizin ilk yanık tedavi birimi deneyimimiz paylaşılarak yanık yaralanmalarının tedavisinde "yanık odasının" öneminin vurgulanması amaçlanmıştır.

\section{Materyal ve Metod}

Çalışma Haziran 2020- Nisan 2021 tarihleri arasında Yozgat Şehir Hastanesin'de retrospektif olarak gerçekleştirildi. Bozok Üniversitesi Klinik Araştırmalar Etik Kurulundan etik onayı alındı (Kayıt numarası: 2017-KAEK189_2021.03.31_07). Bu süreç içerisin de "yanık odası" birimimizde yatırılarak veya poliklinikte ayaktan tedavi edilen hastalar çalışmaya dahil edildi. Hasta bilgileri hastane elektronik kayıtlı verilerden elde edildi. Hastaların yaş, cinsiyet, yanık nedeni, toplam yanık yüzey alanı, yanık bölgesi, hastane yatış süresi, uygulanan tedavi yöntemleri belirlendi. 0-12 yaş "çocuk", 13-18 yaş "genç", 18-65 yaş "yetişkin" ve 65 yaş üstü "yaşlı" hasta olarak kabul edildi. Yanıklar yaralanmaları; haşlanma yanığı, alev yanığı, elektrik yanıkları olarak gruplandırıldı. Yanık yüzey alanı yetişkinlerde dokuzlar kuralına göre, çocuklarda ise LundBrowder yöntemine göre hesaplandı. Yanık oranları toplam vücut yüzey alanının \% 0-5, \% 6-10, \% 11-15 olarak gruplandırıldı. Yüzeyel epidermis yanıklar (1.dereceden) çalışmaya alınmadı. Yanık yaralanmaları; yanı̆ı̆n derinliğine göre 2.dereceden yüzeyel, 2.dereceden derin ve 3.dereceden yanıklar olarak tanımlandı. Yanık bölgeleri; baş, gövde, üst ekstremite ve alt ekstremite olarak gruplandırıldı. Boyun ve yüz yanıkları; baş bölgesi, göğüs, karın, sırt ve bel yanıkları; gövde bölgesi, her iki el ve kol yanıkları; üst ekstremite bölgesi , her iki ayak, bacak, uyluk ve kalça yanıkları; alt ekstremite bölgesi olarak belirlendi. Yara temizlenmesi ve pansumanında; yaralar oda sıcaklığında çeşme suyu, serum fizyolojik veya nötral pH'lı sıvı sabunlar kullanıldı. Batikon, betadin gibi povidin iyot içe- ren antiseptik solüsyonlar kullanılmadı. Pansuman tedavisi, bactrigas (Smith\&Nephew), gümüş kaplı örtüler (Leina-Werke) veya yağlı merhem veya pomad (gümüş sülfadiyazin, mupirosin, nitrofurazon) emdirilmiş gazlı bezlerle yapıldı. Standart pansuman dışında bazı uygun hastalara kısmi kalınlık da deri grefti yada plasenta uygulaması önerildi. Bu işlemleri kabul eden hastalara bilgilendirilmiş onamı alındıktan sonra bu prosedürler uygulandı. Kategorik veriler sayı ( $n$ ) ve yüzde (\%) olarak, numerik veriler ortanca (aralık, en alt, en üst) olarak gösterildi. SPSS22 (Inc, Chicago, IL, USA) yazılımı kullanılarak tanımlayıcı ve karşılaştırmalı istatistiksel analiz yapıldı. Numerik verilerde Mann-Whitney U testi, kategorik verilerde Pearson Chi-Square testi ve Fisher's Exact Test (Fisher-FreemanHalton Exact Test) uygulandı. Sonuçlar \%95'lik güven aralığında, anlamlılık $p<0.05$ düzeyin de değerlendirildi.

\section{Bulgular}

İlimizin ilk "yanık odası" birimi gerekli alt yapı hazırlıklarından ve izinler alındıktan sonra, 2020 yılı haziran ayında hasta kabulüne başlamıştır. Yanık tedavileri gerekli sertifika ve deneyime sahip Genel Cerrahi uzmanı sorumluluğu altında gerçekleştirilmektedir. Çocuklarda toplam vücut yüzey alanının \% 10'una kadar, diğer hastalarda toplam vücut yüzey alanının \% 15'ine kadar olan 2.dereceden yanıklar ile yaş sınırlaması olmaksızın toplam vücut yüzey alanının \% 2'sine kadar olan 3.dereceden hafif ve orta yanık yaralanmaları merkezimizde tedavi edilmektedir. Inhalasyon, kimyasal, perineal, genital, bazı yüz ve eklem bölgesi yanıklar ile çoklu travma ve yoğun bakım ihtiyacı olan yanık yaralanmaları bir üst merkeze sevk edilmektedir.

Hastanemizde ayaktan veya yatırılarak tedavi edilen toplam 107 hastanın 57'i (\% 53,3) erkek, 50'si (\% 46,7) kadındı. Bu hastaların ortanca yaş değeri 24 (aralık, 1-88) idi. Tüm hastaların cinsiyet ve yaş gruplarına göre dağılımı Grafik 1'de gösterildi. Yatarak veya ayaktan tedavi edilen hastaların etiyolojik nedenlerinin, $85(\% 79,4)$ hastada haşlanma yanığı, $21(\% 19,6)$ hastada alev yanığı ve 1 $(\% 0,9)$ hastada elektrik yanığı olduğu görüldü (Tablo 1$)$. Haşlanma yanıkları ağırlıklı olarak çay, sıcak su ve sıcak süt den kaynaklanırken, alev yanıkları daha çok tandır, soba, tüp ve ocak kaynaklı kazalardan meydana gelmişti. Gövde yanıkları $47(\% 45,8)$ hastada görüldü ve en sık etkilenen bölgeydi. Baş yanıkları $8(\% 7,5)$ hasta görüldü ve vücudun en az yaralanan bölgesiydi (Tablo 2). Yanık derinliği yönünden en sık karşılaşılan yanık yaralanmaları 2.dereceden derin yanıklardı. Bu durum 58 (\% 54,2) hastada saptandı (Tablo 2). Hastaların yanık bölgeleri, toplam yanık yüzey alanı ve yanık derinlikleri Tablo 2'de özetlendi. Hastaların $21^{\prime}$ inde $(\% 19,6)$ en az bir yandaş hastalık vardı. Bunlar sırasıyla 19 (\% 63,3) hastada hipertansiyon, 9 (\% 30) hastada tip 2 diabet hastalığı ve $2(\% 6,6)$ hastada kronik obstrüktif akciğer hastalığıydı. Yedi hastada birden fazla yandaş hastalık bulunmaktaydı. 
Tablo 1. Hastaların demografik özellikleri.

\begin{tabular}{|c|c|c|c|c|}
\hline & $\begin{array}{l}\text { Tüm hastalar } \\
(\mathrm{n}=107, \% 100)\end{array}$ & $\begin{array}{l}\text { Yatarak tedavi }(n=43 \text {, } \\
\% 40,2)\end{array}$ & $\begin{array}{l}\text { Ayaktan tedavi } \\
(n=64, \% 59,8)\end{array}$ & $p$ \\
\hline Yaş & $24(1-88)$ & $33(1-82)$ & $28(1-72)$ & $0,48^{\&}$ \\
\hline Cinsiyet & & & & $0,9^{\#}$ \\
\hline Erkek & $57(\% 53,3)$ & $22(\% 51,2)$ & $35(\% 54,7)$ & \\
\hline Kadın & $50(\% 46,7)$ & $21(\% 48,8)$ & $29(\% 45,3)$ & \\
\hline Yaş grupları & & & & $0,005^{\# \#}$ \\
\hline Çocuk & $35(\% 32,7)$ & $12(\% 27,9)$ & $23(\% 35,9)$ & \\
\hline Genç & $6(\% 5,6)$ & $5(\% 11,6)$ & $1(\% 1,6)$ & \\
\hline Yetişkin & $52(\% 48,6)$ & $16(\% 14,9)$ & $36(\% 56,2)$ & \\
\hline Yaşlı & $14(\% 13,1)$ & $10(\% 9,3)$ & $4(\%$ 6,3) & \\
\hline Yanık nedeni & & & & $<0,001^{\# \#}$ \\
\hline Haşlanma & $85(\% 79,4)$ & $24(\% 55,8)$ & 61 (\% 95,3) & \\
\hline Alev & $21(\% 19,6)$ & $18(\% 41,9)$ & $3(\% 4,7)$ & \\
\hline Elektrik & $1(\% 0,9)$ & $1(\% 2,3)$ & $0(\% 0)$ & \\
\hline Komorbidite & & & & $0,003^{\#}$ \\
\hline Var & $21(\% 19,6)$ & $14^{\&}(\% 32,5)$ & $7 *(\% 10,9)$ & \\
\hline Yok & $86(\% 80,4)$ & $29(\% 67,4)$ & $57(\% 89,1)$ & \\
\hline
\end{tabular}

Tablo 2. Yanık bölgesi, yanık oranı ve yanık derinliğinin dağılımı.

\begin{tabular}{lll}
\hline Yanık alan dağılımı ve oranı & $\mathrm{n}=107$ & $\% 100$ \\
\hline Baş \% 0-5 & 5 & 4,7 \\
Baş \% 6-10 & 3 & 2,8 \\
Baş \% 11-15 & 0 & 0 \\
Gövde \% 0-5 & 26 & 24,3 \\
Gövde \% 6-10 & 21 & 19,6 \\
Gövde \% 11-15 & 2 & 1,9 \\
Üst ekstremite \% 0-5 & 16 & 14,9 \\
Üst ekstremite \% 6-10 & 6 & 5,6 \\
Üst ekstremite \% 11-15 & 1 & 0,9 \\
Alt ekstermite \% 0-5 & 13 & 12,1 \\
Alt ekstermite \% 6-10 & 11 & 10,3 \\
Alt ekstermite \% 11-15 & 3 & 2,8 \\
Yanık derinliği & & \\
2.derece yüzeyel & 32,2 \\
2.derece derin & 43 & 54,2 \\
3.derece & 58 & 5,6 \\
\hline
\end{tabular}

Tablo 3. Yatan hastalarda uygulanan tedavi yöntemleri.

\begin{tabular}{lcc}
\hline & $\mathrm{N}=43$ & $\%$ \\
Pansuman & 33 & $\% 76,7$ \\
Yağlı merhem emdirilmiş gazlı bez & 16 & $\% 37,2$ \\
Batrigas (Smith\&Nephew) & 13 & $\% 30,2$ \\
Gümüş kaplamalı örtü (Leina-Werke) & 4 & $\% 9,3$ \\
Greft uygulama & 4 & $\% 9,3$ \\
Plasenta uygulama & 6 & $\% 14$ \\
\hline
\end{tabular}


Toplam 43 (\% 40,2) hasta yatırılarak tedavi edildi. Bu hastaların yatış süreleri ortanca 3 gün (1-90) olup yaş gruplarına göre yatış süresinin dağılımı Grafik 2'de gösterildi. Hastane yatış süresi yaşlı kadın hastalarda ortalama 24,2 (2-90) gün ile en fazlaydı. En az ise genç kadın hastalarda olup ortalama 2 (0-2) gündü. Yatarak tedavi alan hastaların 24'ünü (\% 55,8) haşlanma, $18^{\prime}$ ini $(\% 41,9)$ alev yanıkları ve $1^{\prime}$ ini $(\% 2,3)$ elektrik yanıkları oluşturmaktaydı (Tablo 1). Yatan hastalarda kadın sayısının ve yaş değerlerinin yüksek olmasına rağmen ayaktan tedavi görenlerle aralarında istatistiksel bir fark saptanmadı (sırasıyla, $p=0,9$ ve $p=0,48)$. Ancak yatırılarak tedavi edilenler ile ayaktan tedavi edilen hastalar arasında "yaş grupları", "yanık nedeni" ve "komorbidite" açısından anlamlı fark olduğu görüldü (sırasıyla, $p=0,005, p=0,001, p=0,003$ ).

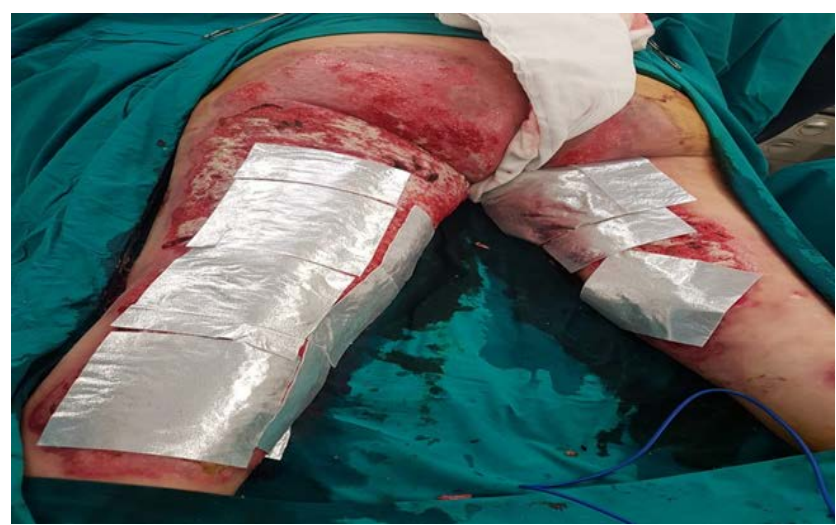

Resim 1: Her iki uyluk arka bölgeye gümüş tedavisi uygulanması.

Yatan hastaların 33'üne $(\% 76,7)$ standart pansuman tedavisi uygulandı. Yağlı merhem veya pomat emdirilmiş gazlı bezle pansuman $16(\% 37,2)$ hastada uygulandı ve bu en çok tercih edilen yöntemdi. Diğer uygulanan pansuman yöntemleri ve oranları Tablo 3'de gösterildi. Gümüş kaplı örtü tedavisi $4(\% 9,3)$ hastada başarıyla uygulandı (Resim 1). Greft tedavisi de sadece 4 (\% 9,3) hastada uygulandı. Bu hastaların tamamında kısmi kalınlıkta greft uygulaması yapıldı (Resim 2). Greft uygulama sonrası herhangi bir komplikasyonla karşılaşılmadı.

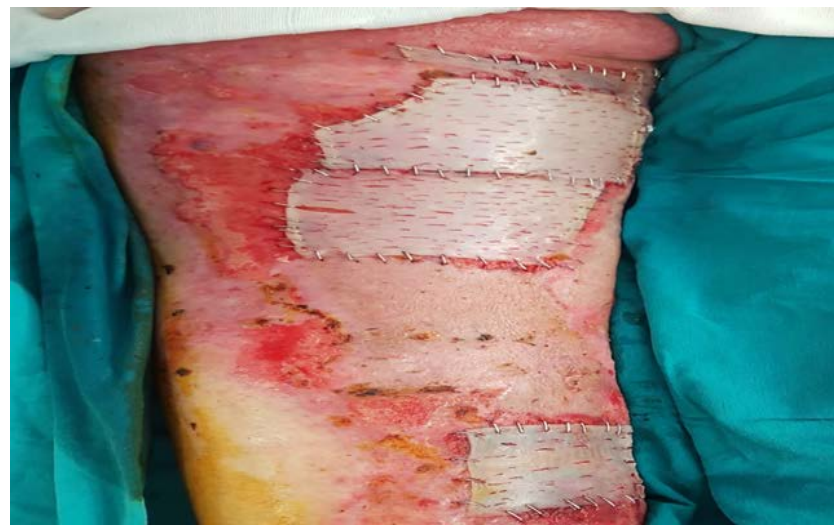

Resim 2: Sol uyluk arka bölgeye greft uygulama sonrası görünüm.

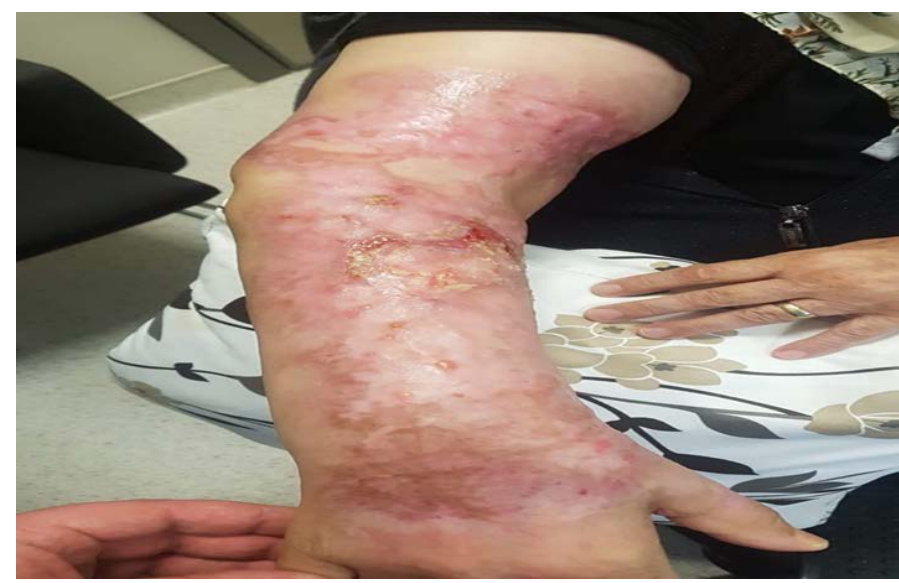

Resim 3: Sağ kola plasenta uygulaması sonrası yanık yarasının görünümü.

Yanık alanına plasenta uygulaması hastaların 6'sında (\% 14) yapıldı (Tablo 2). Plasenta uygulanan bölgeler hastaların üçünde üst ekstremite, ikisinde alt ekstremite ve birinde gövde kısmıydı. Bu hastaların tümünde 2.dereceden derin haşlanma yaralanması vardı. Ortanca yaş değeri $56,5(13,75)$ olup, üçü hipertansiyon ve biri tip 2 diyabet hastasıydı. Plasenta tedavisi sonrası takiplerde tatminkar yara iyileşmesi görüldü (Resim 3). Ayaktan veya yatırılarak yanık tedavisi uygulanan hastalarımızın hiçbirinde mortalite görülmedi.

\section{Tartışma}

Yanık yaralanmalarının \% 40,2'si yatırılarak tedavi edildi. Bu hastaların \% 76,7'sinde standart pansuman tedavisi, $\% 23,3$ 'de ise greft veya plasenta uygulaması gibi farklı tedavi yöntemlerinin tercih edildiği ve bu tedavilerin tümünde tatminkar sonuçlar alındığı saptandı.

Ülkemizde yanık tedavi birimleri “yanık odası”, "yanık ünitesi" ve "yanık merkezi" olarak sınıflandırılmaktadır. Bu birimlerde çalışan hekimin Genel cerrahi uzmanı, Çocuk cerrahisi uzmanı veya Plastik, Rekonstrüktif ve Estetik cerrahi uzmanlıklarından birine sahip olması gerekmektedir (6). Sağlık Bakanlığı, hastaların çocuk veya erişkin olma durumuna, yanığın yüzey alanı ve derinliğine, etiyolojik sebeplerine göre hastalarda bir tedavi algoritması önermiş ve yanık birimleri arasındaki sevk kriterlerini belirlemiştir (2). Sevk kriterleri hastanemiz alt yapısı ve hastaların il dışına gitmekteki isteksizliği de göz önünde bulundurarak yanık birimimizde nispeten daraltıldı. Ancak çoğunlukla kırsal nüfusa hizmet vermemiz, optimal yara bakımına ilişkin endişelerden dolayı da yatış endikasyonları genişletildi. Yaklaşık \% 40 düzeyinde olan yatış oranlarımızda bunu göstermektedir. Nitekim hastanenin alt yapısı ve bulunduğu bölgenin yerel koşullarının da, yatış veya ileri merkeze sevk konusunda belirleyici bir etken olabileceği literatür verilerinden anlaşılmaktadır (5).

Yanık toplumda her yaştan insanı etkilemektedir. Çalışmamızda bu değerler 1 yaşından 88 yaşına kadar değişen geniş bir yelpazeye sahipti. Erkek cinsiyet daha fazlaydı 
ancak bu anlamlı bir fark değildi $(\% 53,7)$. Ülkemiz veya yurtdışı kaynaklı yapılan yüksek volümlü çalışmalarda erkek cinsiyetin ağırıklı olduğu görülmektedir (4-9). Bu durum erkek çocuklarının kız çocuklarına göre daha hareketli yapısı, erkeklerin iş hayatında daha aktif olması veya erkeklerin ev işlerinde daha tecrübesiz olması gibi etkenlerle açıklanmıştır (4-9) .

Genel olarak yanık travmalarının çoğunluğu haşlanma ya da alev yaralanmalarından oluşur

$(4,6,7)$. Bu tür kazaların yaklaşık \% 80'i ev veya iş yerinde meydana gelmektedir (1). İlimizde haşlanma yanıkları ağırlıklı olarak çay, sıcak su ve sıcak süt den kaynaklanırken, alev yanıkları daha çok tandır, soba, tüp ve ocak kaynaklı kazalardan meydana gelmiştir.

Bu çalışmada hastaların \% 99' unu haşlanma ve alev yanıkları oluşturuyordu. Bu yüksek oranlar, sevk zincirine göre hafif yanık vakalarının yanık birimimize yönlendirilmesine ve ilimizin bir sanayi kenti olmayışına bağlamaktayız. Bu çalışmada 18-65 yaş aralığı yanık hastalarının en sık görüldüğü gruptu. Daha dar yaş gruplarının incelendiği çalışmalarda çocuk ve yaşlılarda yanık insidansının fazla olduğu gösterilmiştir (7). Ancak bu durumun sosyo-ekomik ve kültürel koşullara göre farklılık gösterebileceği aşikardır (10).

Yanık hastalarında ileri yaş, eşlik eden yandaş hastalığın olması, yanık alan genişliği ve derinliğinin büyüklüğü mortaliteyle yakından ilişkilidir $(11,12)$. Buna ek olarak bazı çalışmalarda kadın cinsiyeti ve alev yanıklarının da mortalite yönünden bağımsız birer risk faktör olduğu ileri sürülmüştür $(8,13,14)$. Bu çalışmada 65 yaş üstü kadın hastaların en uzun yatış süresine sahip olduğu, alev yanıklarının da sadece hastaların yatırılarak tedavi edilmesinde anlamlı bir faktör olduğunu saptadık. Ancak her iki durumunda mortaliteye yol açmadığını gördük. Bu çalışmada hasta kaybedilmemesini riskli, ağır yanık vakalarının ileri yanık merkezlerine sevk edilmesinden kaynaklandığı açıktır.

Çalışmamızda yanıktan en sık etkilen vücut kısmı gövde bölgesiydi. Bahçe ve ark. ise 1453 olgudan oluşan retrospektif çalışmalarında, yanık yaralanmalarının \% 40'nın alt ekstremite bölgesinde olduğunu saptamışlardır (9). Gövde yaralanmaları ise aynı çalışmada \% 20 oranla 3. en sık etkilenen bölge olarak belirlenmiştir. Bu durum yanık hastalarının demografik, etiyolojik farklılıkların yanı sıra yanık hasarının oluştuğu vücut bölgelerininde de önemli oranda değişebileceğini göstermektedir. Yanık yaralanmalarında etkilenen vücut bölgesi morbidite ve mortalite açısından önem taşır. Bazı bölgelerin yaralanmalarında (yüz, el, genital vb) daha spesifik ve ileri merkezlerde tedavi gerektirirken, alt ekstremite yanık yaralanmalarınında da hastanın inmobilizasyonuna bağlı olarak tromboemboli gibi komplikasyonların daha fazla olabileceği ileri sürülmüştür (15) . Yanık yaralanmalarının bel altı ve bel üstü olarak gruplandırıldığı bir çalışmada ise bel altı yanıklarının sadece erkek hastalarda anlamlı olarak mortal seyrettiği saptanmıştır(14). Bu durumu cinsiyetler arası hormonal değişiklikler ile epidermis ve dermisteki yapısal farklılıklara bağlamışlardır.

Standart ve düzenli pansumanlar, yanık yaralanmalarının önemli bir kısmında yeterli tedavi sağlamaktadır (4-6, 8, 9). Bu çalışmada pansuman tedavisinin yanı sıra greft ve plasenta uygulaması gibi farklı tedavi yöntemleri de kullanıldı. Greft ile kapama sadece 4 hastada yapıldı ve tümünde kısmi kalınlıkta greft kullanıldı. Greft uygulamasının; çevresel ısı ve patojenlerden koruma sağladığı, sıvı kaybını önlediği ayrıca iyileşme sürecini hızlandırdığı bilinmektedir. Greft uygulamasında epidermis ile birlikte dermisin bir kısmı alınır ve genellikle uyluk, sırt veya karın bölgesi tercih edilir (16). Bu nedenle greft uygulaması düşünülen hastalarda yanık yüzey alanı ve yanık bölgesi de önem taşımaktadır. Bu çalışmada, hastalardaki yanık yüzey alanın düşük olması nedeniyle greft alma açısından sorun oluşturmadığı görülmüştür. Yanık tedavisin de kullanılan bir diğer alternatif yöntem plasenta naklidir. Plasentanın, temel işlevi, besleyici özellikleri ve yapısı nedeniyle yanık dışı yara tedavisinde de kullanılmaktadır. Etik sorun teşkil etmemesi ve düşük maliyeti başlıca avantajlarıdır. Ayrıca hızlı iyileşme ve yara bölgesinde iyi bir anestetik etki yaptığı ileri sürülmektedir (17). Çalışmamızda 6 (\%14) hastada plasenta nakli uygulandı. Aldığımız olumlu sonuçlarla birlikte yanık birimimizde plasenta uygulamasının önümüzdeki süreçte artacağı kanısındayız.

İlimizin ilk ve tek yanık tedavi birimi yaklaşık 425 bin nüfuslu bir bölgeye hizmet vermektedir. Yanık odası birimimiz 10 ayda yaklaşık 107 hastaya ayaktan veya yatırılarak en güncel yanık tedavilerini uygulanmıştır. Yanık yaralanmalarının önemli bir kısmının yanık odası birimlerinde başarıyla tedavi edilebileceği ülkemizdeki benzer yanık tedavi birimlerin deneyimlerinden anlaşılmaktadır (4-6). Aynı zamanda il dışı sevkleri önemli oranda önlendiği bu çalışmalarda gösterilmiştir. Hafif yanıklarda bile belli araIıklarla poliklinik kontrolü gerektiği göz önünde bulundurulduğunda, uzak yanık birimlerine hastaların beli aralıklarla gidip gelmeleri önemli bir zaman ve ekonomik kayıp yaratacak ayrıca yanık merkezlerinin iş yükünü gereksiz bir şekilde artıracaktır(4-6, 9).

Bu çalışmanın başlıca limitasyonu hasta sayısının sınırlı olması, bazı epidemiyolojik verilerdeki (kaza yeri vb.) eksiklikler ve uzun dönem tedavi sonuçlarının değerlendirilmemiş olmasıdır. İlimizin yanık hastalarına hizmet veren yanık tedavi biriminin deneyimini ilk kez yansıtması çalışmanın güçlü yönüdür. Ayrıca yanık tedavisiyle ilgilenmek isteyen hekimleri ve hastane yönetimleri cesaretlendireceği, motive edeceğine olan inancımız da bu çalışmayı değerli kılmaktadır.

Yanık yaralanmaları tedavisinde ikinci basamak hastanelerde mevcut alt yapı düzenlemeleri ve konu üzerine yetkin ekiple "yanık odası" birimlerinde başarılı sonuçlar elde edilebilir. Bu yanık tedavi birimleri sayesinde ileri yanık merkezlerinin iş yükü azaltılmış ve ülke kaynakları daha etkili kullanılmış olacaktır. 
Etik onam: Çalışma için Bozok Üniversitesi Klinik Araştırmalar Etik Kurulundan etik onayı alındı (Kayıt numarası: 2017-KAEK189_2021.03.31_07).

\section{Yazar Katkıları:}

Konsept: S.K.

Literatür Tarama: E.H., S.K.

Tasarım: S.K.

Veri toplama: E.H.

Analiz ve yorum: S.K.

Makale yazımı: E.H., S.K.

Eleştirel incelenmesi: S.K.

Çıkar Çatışması: Herhangi bir çıkar çatışmamız bulunmamaktadir.

Finansal Destek: Araştırma kapsamında herhangi bir kurum ya da kuruluştan finansal destek sağlanmamıştır.

\section{Kaynaklar}

1. Dissanaike S, Ha D, Mitchell D, Larumbe E. Socioeconomic status, gender, and burn injury: A retrospective review. Am J Surg. 2017; 214(4):677-81.

2. Algoritması. SHDBT. Yanık yaralanmaları tedavi algoritması T.C. Sağlık Bakanlığı; 2012 [cited 2012]. Erişilebilir: https://khgmsaglikhizmetleridb.saglik.gov.tr

3. Alexander $M$, Chaudry IH, Schwacha MG. Relationships between burn size, immunosuppression, and macrophage hyperactivity in a murine model of thermal injury. Cell Immunol. 2002; 220(1):63-9.

4. Sıkar HE, Yurdakul Sıkar E. Afyonkarahisar Devlet Hastanesi'nde yanık nedeniyle tedavi edilen hastaların değerlendirilmesi: retrospektif çalışma. Kocaeli Tıp Dergisi. 2018; 7(1):92-5. 5. Özçetin B, Tihan D, Demirci H, Altintaş MM, Arayici V, Taha A. Yeni kurulan bir yanık merkezinde 2.5 yıllık deneyim. Turkish Journal of Surgery/Ulusal Cerrahi Dergisi. 2012; 28(3):146-48.

6. Çınal H, Barın EZ. Bir Yanık Ünitesinin 5 Yıllık Deneyimi: 667 Yanık Olgusunun Incelenmesi. Van Tıp Dergisi. 2020; 27(1):5662.

7. Crowe CS, Massenburg BB, Morrison SD, Naghavi M, Pham TN, Gibran NS. Trends of burn injury in the United States: 1990 to 2016. Ann Surg. 2019; 270(6):944-53.

8. Alipour J, Mehdipour Y, Karimi A. Epidemiology and outcome analysis of 3030 burn patients with an ICD-10 approach. Ann Burns Fire Disasters. 2020; 33(1):3.

9. Bahçe ZŞ, Öztaş T. Epidemiological analysis of patients with burns in third-line hospitals in Turkey. Int Wound J. 2020; 17(5):1439-43.

10. Park JO, Shin SD, Kim J, Song KJ, Peck MD. Association between socioeconomic status and burn injury severity. Burns. 2009; 35(4):482-90.

11. Knowlin L, Stanford L, Moore D, Cairns B, Charles A. The measured effect magnitude of co-morbidities on burn injury mortality. Burns. 2016; 42(7):1433-8.

12. Forbinake NA, Ohandza CS, Fai KN, Agbor VN, Asonglefac BK, Aroke $D$, et al. Mortality analysis of burns in a developing country: a CAMEROONIAN experience. BMC Public Health. 2020; 20(1):1-6.

13. Williams FN, Strassle PD, Knowlin L, Napravnik S, van Duin D, Charles A, et al. Sex-based differences in Inpatient burn Mortality. World J Surg. 2019; 43(12):3035-43.

14. Mohammadi AA, Pakyari MR, Jafari SMS, Tavakkolian AR, Tolide-le HR, Moradi Z, et al. Effect of burn sites (upper and lower body parts) and gender on extensive burns' mortality. Iran J
Med Sci. 2015; 40(2):166.

15. Mohammadi AA, Johari HG. Interesting differences between the burns involving the upper versus lower extremities. J Trauma. 2009;66(6):1746-7.

16. Braza ME, Fahrenkopf MP. Split-Thickness Skin Grafts. StatPearls. Treasure Island (FL): StatPearls Publishing Copyright (c) 2021, StatPearls Publishing LLC.; 2021.

17. Klama-Baryła A, Łabuś W, Kitala D, Kraut $M$, Nowak $M$, Kawecki M. Experience in Using Fetal Membranes: The Present and New Perspectives. Transplant Proc. 2018; 50(7):2188-94. 